\title{
The effect of supply chain management in governance: Public sector perspectives
}

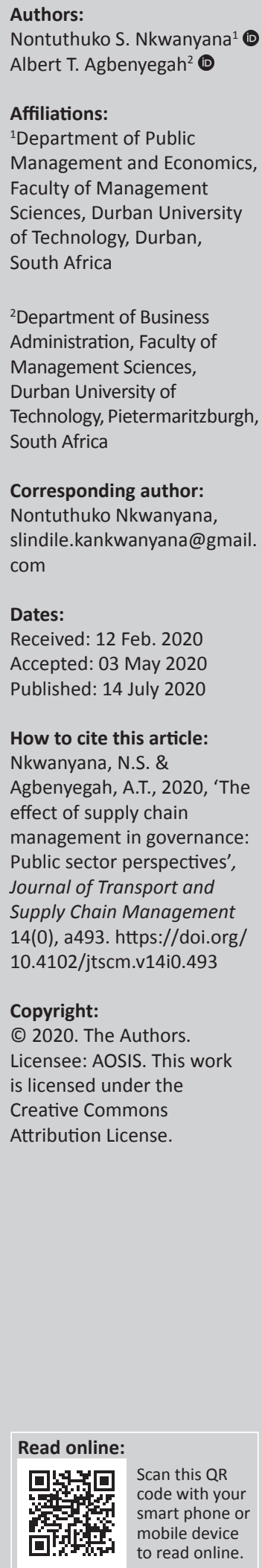

Background: Supply chain management (SCM) was introduced as a remedy to irregularities of the past procurement models in public sector. Since its inception, literature has exposed a number of irregularities and deficiencies in the acquisition management processes within $\mathrm{SCM}$ in this sector.

Objectives: This article explores a case study of KwaZulu-Natal to ascertain the current status of SCM in the aspect of acquisition of goods and services in relation to issues of good governance and human resource capital. It aims to determine the underlying factors that have given rise to the reported irregularities and deficiencies.

Method: This article draws on quantitative data collected using a five-point Likert scale questionnaire, from ' 1 ' strongly disagree to ' 5 ' strongly agree. The study sample consisted of 129 participants. The data collected were analysed using the Statistical Package of Social Sciences tool.

Results: The findings of the study indicate that there is (1) a notable human resource deficiency, (2) inadequate knowledge regarding the processes employed in the acquisition of goods and services within SCM and (3) a lack of adequate training. The study also notes best practices such as (1) a high level of accountability, (2) conformity of relevant laws, (3) transparency, (4) responsiveness and (5) participation.

Conclusion: This study rejects the current assumptions that the acquisition process of the SCM system is flawed, and rather confirms the forever growing assumptions related to human resources capacity, knowledge and skills deficiencies as possible root causes of the reported irregularities and deficiencies.

Keywords: supply chain management system; supply chain management processes; acquisition; management.

\section{Introduction}

Prior to 2003, a number of concerns related to procurement systems of the past were brought to the notice of the government of the Republic of South Africa (RSA). Mainly these systems were reported to be associated with gross irregularities. Lack of accountability and supporting structures, fragmented processes and inconsistent application of policies were some amongst the disorders of these past procurement models (De Lange 2011). These resulted in the disregard of service delivery as well as a lack of infrastructure development. Therefore, reforms became necessary, which led to the adoption of supply chain management (SCM). Supply chain management was introduced as a powerful system to aid and remedy the irregularities of past procurement models of public sector. It was declared to hold the promise of better procurement systems in South Africa (SA) as it conforms to internationally best accepted standards (Migiro \& Ambe 2008:231). Unlike past models, this system was reported to be characterised by conformity to the principles of good governance, namely, fairness, competitiveness, equitable administration, transparency and cost-effectiveness (National Treasury Regulations 2005:50). In addition, it mandated organs of the state to accordingly deploy and train SCM officials (National Treasury Regulations 2005:50). As such, this presented a likelihood of enhancing both performance and compliance. One of the major parts of SCM is the acquisition of goods and services. This aspect is concerned with buying or purchasing or procurement of goods and services. With the adoption of SCM model, an organisation, its customers and its suppliers are brought together in the pursuit of fulfilling customers' orders. Therefore, from an SCM perspective, organisations do not operate in 
silos; instead, they are in partnership with suppliers and customers to achieve a common goal. According to Wisner, Tan and Leong (2012:4), the nature of relations with customers and suppliers determines the degree of business success. Accordingly, Mbanje and Lunga (2015:3) believe that with the adoption of SCM, organisations would be able to survive because of better procedures that create necessary platforms for customer satisfaction and maximum cost reduction measures. Surprisingly, although SCM is characterised by many pointers of business success as depicted above, there has been a recurring observation that this model also operates in the midst of a number of irregularities and deficiencies. Reported irregularities include gross non-adherence to set laws that has resulted in unauthorised, wasteful and irregular expenditure (Stemele 2009:68), misappropriation of state funds (De Lange 2011), lack of standardised processes and procedures, and disregard for tender documentation (McCarthy 2006). Moreover, officials cannot account for large sums of procurement funds. Over $20 \%$ of the procurement budget is still misused by officials through the payment of exorbitant prices for goods and services. At times, officials fail to monitor the expenditure. As such, communities are unable to realise socio-economic advancement and improvement in the general quality of life, as they had been promised through chapter 2 of the Constitution of RSA (De Lange 2011). These irregularities and deficiencies possess the potential risk of adversely affecting the financial standing of the country as a whole. As part of continuous monitoring and evaluation in the quest to pursue better performance of the system and to aid in discontinuing the wastage of public funds, this study aims to explore SCM practices so as to gain insights into the current status of SCM in relation to governance and human resource capability. The study thereby seeks to explore SCM processes to provide insights and/or recommendations to support the model to become efficient and effective and further determines what could be the underlying factors that have given rise to the reported irregularities and deficiencies.

\section{Key concept: Supply chain management Origin of supply chain management}

Supply chain management could be traced back to 2003, in the public sector, when it was officially adopted by the RSA cabinet. It originated as a vital functioning of financial management that entails processes producing end customer goods and services. Theoretically, SCM is defined as an action that collaborates and coordinates 'events or processes' between various parties. As such, Nagy (2010:20) defines it as an integrative management philosophy where all partners cooperate in instituting pioneering solutions in order to deliver sound customer service. Mentzer et al. (2001:18) further argue that SCM is a systemic, strategic coordination of traditional business functions aimed at improving the long-term performance of entire chain. On the other hand, National Treasury Regulations (2005:49), subsection 16A3.2, present SCM as being concerned with the acquisition of goods and services, letting and disposal of all assets no longer required by the state. Migiro and Ambe (2008:23) further state that SCM seeks to introduce internationally best accepted practices whilst addressing a government's preferential procurement policy objectives. According to these authors, one of the broader objectives of SCM is the elevation of principles of good governance. Within the procurement environment, it is characterised by the elements of participation, transparency, responsiveness, accountability and adherence to the rule of law (National Treasury Regulation 2005:46). According to the Institute of Local Government Management of South Africa (2010:1), good governance is a critical factor for measuring efficiency and effectiveness of an action.

\section{What does supply chain management entail?}

Lee, Kwon and Severance (2007:445) assert that SCM involves cooperation regarding the flow of information and materials or services between different facilities and stakeholders. With the adoption of SCM, activities such as the acquisition, processing, demand creation and fulfilment of all logistics management functions are arranged and controlled centrally. Thus, SCM functions also include coordination and collaboration amongst stakeholders, who can be suppliers, manufacturers, distributors and/or end users. In essence, SCM integrates supply and demand within and across institutions (Marshall et al. n.d.:4). National Treasury Regulations (2005:49) dictate that the acquisition of goods and services through SCM must take place effectively and efficiently. It is deduced from the literature that when a model achieves its goals, regardless of challenges, it is regarded as being efficient and effective. Isoraite (2005:240) argues that a programme is said to be effective if it achieves what it was intended to achieve. Therefore, effectiveness can be described as being concerned with the realisation of results. Bester (2007:7) defines efficiency not only as a cost concerned phenomenon but also as being concerned with the ability of an organisation to deliver on its mandate despite the minimum available budget. Li et al. (2006:111) conclude by echoing that SCM efficiency and effectiveness are the basis of supply chain performance. According to Lichocik and Sadowski (2013:124), this is achieved through setting strategic decisions that are aligned with the future of an organisation and its operations. Similarly, Shaffer and Dalton (2012:101) believe that efficiency and effectiveness are a result of adopting certain SCM practices. The idea is for an organisation to organise its logistical activities or operations in a manner that supports the realisation of better performance. These then become procedures or practices of an organisation. The SCM practices themselves are informed by the supply chain design (SCD) of an organisation (discussed in detail below), which makes tactical choices on the setting up of resources and processes (Melnyk, Narasimhan \& DeCampos 2014:1889). Therefore, it is concluded that the achievement of efficiency and effectiveness is made possible by having a sound value chain throughout the entire SCM process. This includes, amongst other factors, creating an enabling environment to support operations aimed at goal achievement. According to 
Handfield et al. (2011:21), capable human resource is one of the key factors contributing meaningfully to an organisation's strategic growth.

\section{Supply chain design}

Supply chain design is defined as the positioning of resources and processes for the realisation of the desired output over time (Melnyk et al. 2014:1889). To position resources, key partners and their responsibilities are identified, all in an effort to add value to goods and services for end customers (Fawcett, Ellram \& Ogden 2007:216). Melnyk et al. (2014) assert that these partners should be chosen based on core competencies that complement one another. According to Kumar and Nambirajan (2013:86), competence assists organisations to enhance their performance. Concurrently, practices to be adopted in integrating such partners are decided upon. According to Stock and Boyer (2009:700), these practices then inform performance of an organisation. Therefore, performance of an organisation will be as good as the supply chain practices adopted by an organisation (Kumar \& Nambirajan 2013:86). Nel (2010:3) adds that relations or partnerships are informed by the level of complexities within the supply chain systems. For instance, with direct supply chain, relations are only amongst the three partners, that is, organisation, its suppliers and its customers; extended supply chain further extends relations to its supplier's suppliers and its customer's customers; and lastly, ultimate supply chain involves many organisations named as tiers in fulfilling customer needs (Mentzer et al. 2001:4). Nonetheless, SCD builds capacity through cost saving, value adding or both (Christopher 2005:7). Melnyk et al. (2014:1888) support this assertion by arguing that SCD shapes the nature of supply chain, which, in turn, affects supply chain investment decisions which determine the capabilities of a supply chain. Moon (2004:20) mentioned that there is a general consensus that a supply chain structure influences supply chain performance. Therefore, a dysfunctional structure may be expected to yield dysfunctional results or vice versa. According to Fawcett et al. (2007:216-217), where a proper supply chain is not in place, difficulties such as long time-cycles, customer service issues, excessive waste, relatively high inventory, poor coordination of effort and an incompatible information system could occur. To overcome these difficulties, these authors suggest that a group of partnering entities possessing complementary competencies should be identified and brought together through SCD to work towards a common goal. Nel (2010:12) proposes that the following three phases should be followed when designing a supply chain: (1) understanding the nature of end-customer's needs and determining how to meet those needs, (2) selecting a supply chain strategy and (3) scoping the supply chain structure. Basically, Nel (2010) suggests that a proper structure of a supply chain strategy should be built to suit the end-users' needs. This somehow demands some direct relationship between an organisation and its end customers (Nel 2010:3). In fact, relations shall be built amongst all key partners immediately after they have been identified and their roles have been defined. Participants in the public sector supply chain comprise (1) suppliers, who receive purchase orders from public sector organisations; (2) accounting officers or delegated officials, who perform the actual sourcing of goods and services; and (3) customers, who actually take ownership and satisfaction from goods and services rendered. Chopra and Meindl (2010:20) mention manufacturers, suppliers, stores, transporters and dealers, as well as end customers, as part of the supply chain. In order to realise the intended outcomes, supply chain partners and other support structures must be in place across the organisation. In addition, their relations ought to be managed through SCM as a means to guarantee that goods and services are delivered at the right time, right place, right quality and right quantity. Literature, as discussed above, presents efficiency and effectiveness of SCM as an outcome or the result of a number of processes and measures an organisation puts in place for its realisation. This model could be compared with Maslow's hierarchy of needs as indicated by Jerome (2013:4-5), which depicts how one attains self-actualisation, in this instance looking at efficiency and effectiveness of SCM as shown through its performance. Firstly, one must satisfy the very basic (physiological) needs, namely, having sound stakeholder relations in place. Secondly, safety measures should be employed, that is, investment in various resources to support the realisation of SCM goals. These resources are mainly described as treasured, uncommon, imitable and non-substitutable assets (Sarkis, Zhu \& Lai 2011:4). As discussed later, it is not solely the availability of these resources but rather their capability to support an organisation to take advantage of the environment to achieve sustainable competitive advantage (SCA). To achieve this, some of these resources, such as human resources, need to be moulded by an organisation through training (Nkwanyana 2017:9), attitudes and behavioural changes (Obi-Anike \& Ekwe 2014:68) to support its goal. Handfield et al. (2011:21) are also referenced, noting the importance in the quality of organisations' employees. These authors argue that capable human resources in fact determine an organisation's success; however, should an organisation fail to commit to it, SCM is likely to be positioned for failure. Thirdly, a sense of belonging or structure must be created through SCD to determine flow of processes and interconnectedness of partners. Lastly, selfesteem or self-recognition through supply chain practices should be decided upon; according to the above-cited literature, soundness of supply chain practices adopted informs performance, which, in turn, results in efficiency and effectiveness of SCM (see Figure 1).

\section{Why does supply chain management matter?}

Supply chain management was established in line with the requirements of National Treasury Regulations, which prescribe that supply chains shall be managed in a manner that conforms to the principles of efficiency and effectiveness. Therefore, SCM is a legislative requirement aimed at instilling efficiency and effectiveness into the procurement environment. According to Lichocik and Sadowski (2013:124), efficiency 


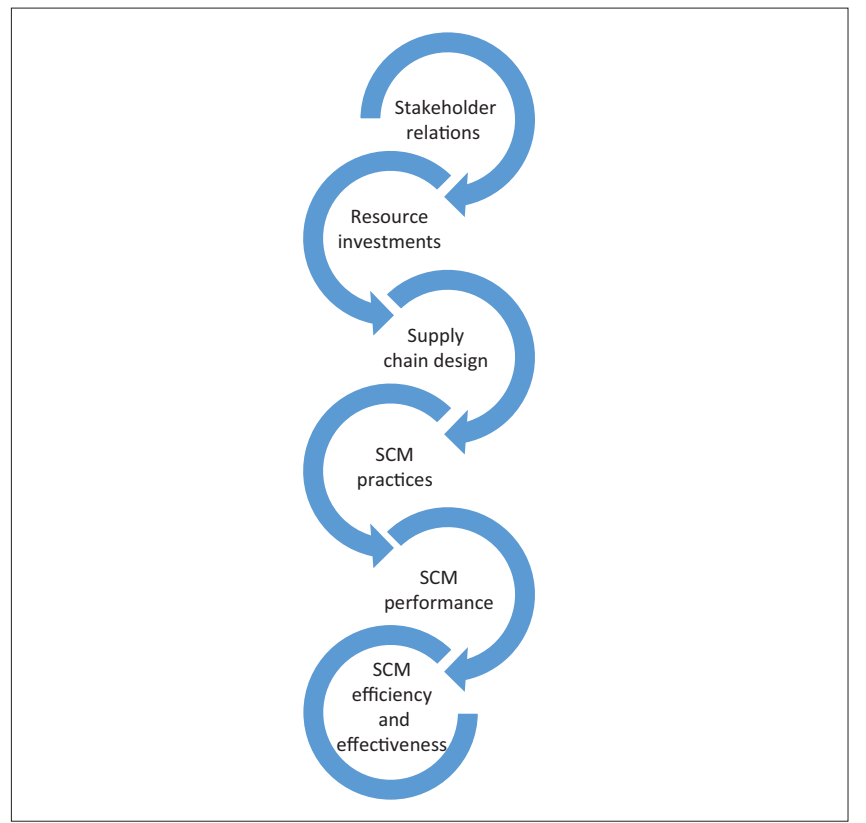

SCM, supply chain management.

FIGURE 1: The performance model of supply chain management.

could be achieved by taking quality-strategic decisions that set up the future operations of an organisation. These authors further argue that an effective supply chain is characterised by being cost-effective, comprising minimal links with reduced processes whilst ensuring that high-quality standards of goods and services are delivered. On the contrary, Bester (2007:7) believes that an organisation's ability to deliver on its objectives within the currently available resources symbolises efficiency. Effectiveness could be defined as the realisation of results. Isoraite $(2005: 240)$ asserts that effectiveness is associated with outcomes, outputs and goal achievement of an action. Supply chain management was thus introduced as a transition to mend the irregularities of the past whilst ensuring better customer service. It was assumed that through principles of fairness, transparency, cost-effectiveness and competitiveness (National Treasury Regulations 2005:49), SCM would be better positioned to combat fraud, ensure better financial management, guide conduct of public servants and promote inclusiveness of those that were previously disadvantaged. On the above basis, SCM has been identified as holding the promise of improving public procurement systems (Ambe 2009:73). As such, it has been declared a cornerstone of service delivery (Dlova \& Nzewu 2014:8).

\section{Theories underpinning supply chain management}

Theories represent ideologies established to describe a group of realities, especially if such ideologies have been tested and found acceptable to make a prediction about a phenomenon (Nyaga 2015:240). Amongst others, (1) complexity theory, (2) theory of constraints (TOC), (3) resource-based theory (RBT) and (4) systems theory (ST) are the foundations of SCM. The complexity theory acknowledges that every system operates amidst order and disorder. Because of the involvement of a number of role-players (Colbert 2004:349), such as clients, service providers, government rules and technological advancements, systems become complex (Sarkis et al. 2011:3). These authors argue that the more these role-players increase, the more it becomes difficult to plan and predict SCM actions, and this could have a direct and indirect influence on the success of an organisation. Similarly, SCM comprises various connections referred to as inter-firm relationships (Pathak et al. 2007:548). The fact that satisfaction of customer's needs is dependent on suppliers outside the control of the focal organisation exposes public sector supply chains to complexity. For organisations to succeed, this compels supply chain managers to be sensitive to the arrangement of their SCM systems as well as to check how each role-player within the chain interacts with the rest (Hearnshaw \& Wilson 2013:443). Nonetheless, Baum (2010:21) maintains that if an organisation possesses relevant tools to take advantage of complexity, then complexity could become a source of gain. The theory of constraints recognises that all systems have at least a single constraint that hinders the attainment of its goals (Hugos 2011:191; Husby 2007:53). Husby (2007:53) identifies equipment, procedures, policies, manpower, process stability and scheduled work time as some of the constraints in the system. Because of systems' uneven capabilities, when one constraint discontinues, another one originates in another part of a system (Hugos 2011:191). As such, the management of constraints becomes a continuous task. According to Ainapur, Singh and Vittar (2012:102), for an organisation to keep abreast of its constraints, it must (1) identify limitations in the system which may be carried out via internal and external audit reviews and/or peer reviews; (2) an organisation should exploit the limitation by avoiding waste and maximising capabilities, activities and operations without any additional resources added; (3) in an organisation, the work of a member causing bottlenecks should be delegated to his or her equivalents. Chou, Lu and Tang (2012:4687) argue that this is a challenging task, as it may be faced with resistance. With time, measures must be developed to alleviate constraints (4) and (5) through continuous system enhancement, an organisation could achieve its goal to finally overcome inertia - with a note, however, that once stage 5 is reached, stage 1 must be repeated, as another constraint could have developed in another part of the system (Ainapur et al. 2012:102). These authors assert that objectives of TOC could be met if an organisation is able to devise a robust measuring, monitoring and controlling method of dealing with constraints using key performance indicators (KPIs). The resource-based theory, also known as resource-based view (RBV), refers to a group of resources linked to an organisation for a particular period (Lockett, Thompson \& Morgenstern 2009:10). These resources could include, but are not limited to, physical assets, capabilities, organisational processes and information. According to Francisco (2015:50), RTB aims to enhance capabilities and roles of these resources in an effort to improve SCA and performance (Yang 2009:1260). Most importantly, resources alone are inadequate; their capacity needs to be created, and their functionality, efficiency and effectiveness when combined would yield SCA (Lockett et al. 2009:10). 
Nkwanyana (2017:9) believes that it is through training that the skills and competencies of employees could be promoted. On the other hand, transforming the attitudes and behaviours of employees increases their capacity to work towards the realisation of organisational goals (Obi-Anike \& Ekwe 2014:68). Lastly, the ST is defined as a theoretical perspective that analyses the phenomenon as a whole, rather than as parts in the whole phenomenon (Mele, Pels \& Polese 2010:127). The systems theory suggests that various components of a complex supply chain, that is, human, information, financial resources, etc., shall be brought together to form part of a subsystem, which is a part of a larger network. Moreover, in order to gain perspective of an entire organisation, ST must be employed to understand the internal and external factors that influence supply chain performance.

\section{Supply chain management model}

As the public sector adopted SCM reforms, the following elements were adopted as a means to operate within the new system. These include demand management, acquisition management, logistic management and performance and risk management processes. These were reported to be means for segregation of duties, giving assurance of oversight roles in the process and thereby minimising risks. As shown by the National Treasury Regulations (2005:49), the idea of this model was to separate functions into the following: if identification and specification of need occurs (demand management); this will inform the purchasing of goods and services (acquisition); thereafter transportation and inventory decisions (logistics); and finally, getting rid of items no longer required (disposals). Figure 2 depicts the various elements of SCM processes as adopted by the government of RSA.

\section{Supply chain management in the public sector perspective}

Despite its promise, SCM, since its inception in public sector, has been marred by various forms of irregularities and deficiencies. As a result, there have been ongoing intense public debates about poor governance and a lack of consequence management, where non-compliance of laws has been identified in SCM (De Lange 2011; Pauw 2011;

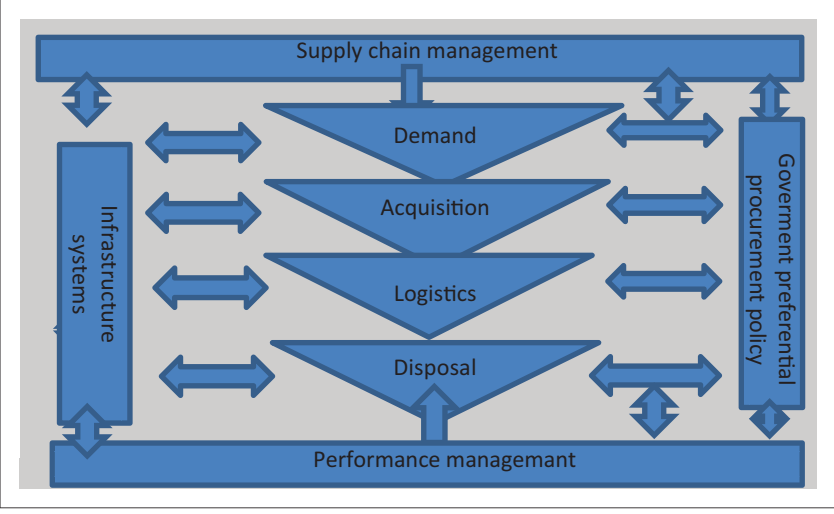

Source: South Africa. 2004. National Treasury Guide for accounting officers or authorities Pretoria: Government Printer.

FIGURE 2: Supply chain management model.
Smart Procurement 2011). Most recently, in 2014-2015 to 2018-2019 financial reporting periods, the Auditor General of South Africa (AGSA) revealed poor administration of contractor performance, wherein projects were delayed, and goods and services were of poor quality and without monitoring, which in turn had affected service delivery. Non-adherence with SCM prescripts remains high (Migiro \& Ambe 2008:236; Tshamaano 2012:48-51), and as such calls for action. For instance, as recent as in 2019, the integrated annual report (Auditor General South Africa [AGSA] 2019) has revealed that the top three projects failed because of, amongst other factors, poor financial management and a lack of corrective actions to address project failures and SCM irregularities. This follows media reports, as debated in parliament in October 2019, about billions in irregular, fruitless and wasteful spending that occurred in the financial year 2018-2019 (Parliament of Republic of South Africa 2019). According to the report, this level of financial mismanagement and wastage of funds was a shock. Other areas of deficiencies include non-payment of service providers, political influences during tender processing, sub-standard estimates of criteria and unstable tender procedures. Auditor General of South Africa blames this on poor planning, inadequate practices, lack of credible reporting and accountability, and inadequate monitoring by all role-players involved in the SCM process. As such, efficiency and effectiveness of SCM cannot be confirmed. However, as mentioned earlier, best practices yield better performance (Kumar \& Nambirajan 2013:87). Therefore, the weakness in this system and its reported failures that had resulted in so many hullabaloos throughout the country could be an indicator of wrong practices that were taking place and/or their incorrect application. As such, an urgent need exists to zoom into SCM practices to examine their correctness and fitness to support good governance as well as the commitment of public service towards developing capable human capital to achieve enhanced customer service.

\section{Research method and design}

To enable the establishment of comprehensive and circumstantial data about the subject matter, a case study design was adopted in this study. Case studies involve the use of single organisation to gather data that define the situation about a research problem that exists in other similar organisations. This method is advantageous in gaining an understanding of a complex subject (Crowe et al. 2011:1). It is used for the generation and testing of new theory. This study is also exploratory as it seeks to divulge information where little is known about a phenomenon (Kumar 2011:335). This approach is appropriate as it provides a deeper ontological understanding of SCM processes and its practices in relation to their correctness and fitness to support good governance and commitment of public sector towards developing capable human capital in order to achieve enhanced customer services. The authors selected one of the national departments in the province of KwaZulu-Natal (KZN) in SA as a population of study. From an estimated total number of about 232 relevant persons, 
namely, 36 middle managers, 37 supervisors and 159 junior staff members, a sample of 150 (23 middle managers, 24 supervisors and 103 junior staff members) was selected. Of those, 129 respondents subsequently took part in the study. This included 19 middle managers, 16 supervisors and 94 junior staff members, resulting in an overall response rate of $86 \%$. Purposive sampling was adopted because of the fact that one of the authors is familiar with the population of interest (Bless, Higson-Smith \& Sithole 2013:172). Only persons involved in the SCM processes were considered and finally included in the sample. At least one person from a total of 79 offices in the province was selected to participate in the study. Additional persons were selected in each office based on office size: the bigger the office size, the more the participants were selected to participate. This was to ensure representation of total population. Quantitative primary data of this study were collected using a five-point Likert scale questionnaire. According to Sekaran (2006:236), a questionnaire is a measuring instrument with a predesigned set of written questions to be answered by subjects. A set of closed-ended questions was developed by the authors and piloted with a small group of persons to ensure its relevance, accuracy, completeness and that it was free from error. Therefore, it could be regarded as a valid and a reliable measure. Questionnaires were distributed via email to a sample utilising blind copy (bcc) so as to avoid possible collusion of respondents in providing responses. Although an instruction was given to respondents to send back responses via fax rather than through email, challenges surrounding access to fax facilities and network issues resulted in a number of responses being received via email. In spite of the delay, no specific bias was experienced because all the responses were received and included in the analysis at one stage. However, confidentially was still maintained by the present authors by simply printing and sequentially coding all received responses and not by name of respondents (i.e. M1, S1, J1, etc.). All received data were validated for completeness; all such questionnaires were rejected if some questions were not answered. All qualifying data were analysed using the Statistical Package of Social Sciences (SPSS) version 23.0.

\section{Preliminary findings from primary data}

The results below illustrate the findings of this research study. These are in line with the requirements of good governance which prescribes that a system conforms to good governance if it is characterised by the elements of participation, transparency, responsiveness, consensus orientation, equity and inclusiveness. A test was made to ascertain the level of participation, transparency, responsiveness and conformity to the laws of an SCM system in public sector.

Figure 3 shows that $59(45.7 \%)$ participants agreed that SCM has led to better end-user participation. In addition, 33 $(25.6 \%)$ participants strongly agreed with the statement. Only a few (i.e. $n=3 ; 2.3 \%$, and $n=11 ; 8.5 \%$ ) either strongly disagreed or disagreed with this statement, whilst 23 (17.8\%)

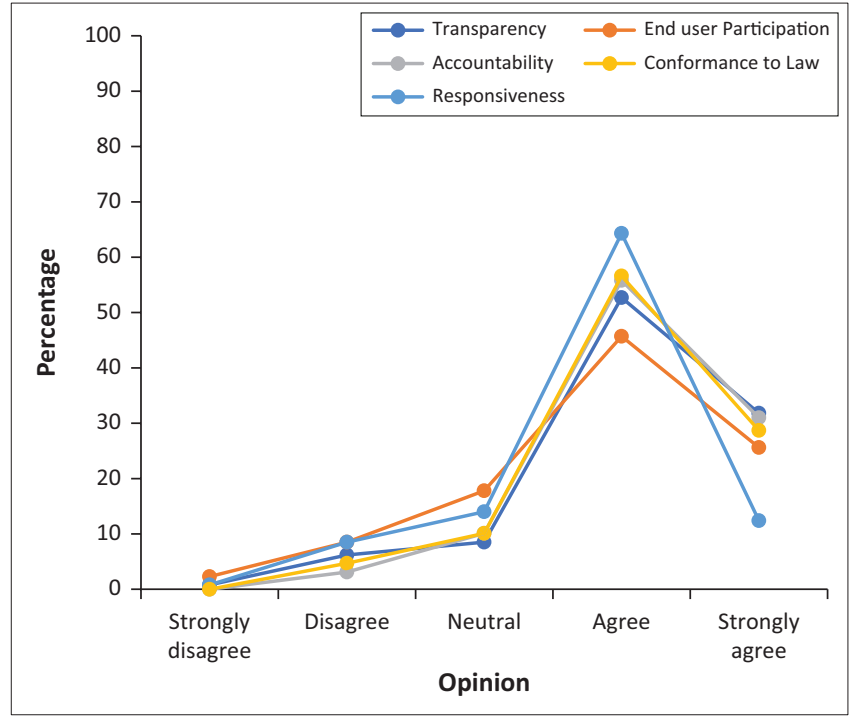

FIGURE 3: Good governance.

remained unsure. Again, the findings of this study rejected claims made by Fourie and Poggenpoel (2016:6), who have reported public sector transparency disorder. Instead, it shows conformity to the basic requirements of the Constitution of the RSA Act No. 108 of 1996, the Preferential Procurement Policy Framework Act No. 5 of 2000 (PPPFA) and the BroadBased Black Economic Empowerment Act No. 53 of 2000 (BBBEEA), which prescribes that SCM must be characterised by transparency, amongst other principles. This is because a large number of participants, totalling 109 (84.5\%), either strongly agreed or agreed with the statement that SCM resulted in transparency. Only a few $(n=8 ; 6.2 \%)$ had rejected the transparency of this system, whilst only one participant $(0.8 \%)$ strongly disagreed. Again, only 11 participants $(8.5 \%)$ were neutral on this matter, as depicted in Figure 3. In relation to responsiveness, as shown in Figure 3, there were reasonable numbers to suggest that the system was responsive to customer needs, since 83 (64.3\%) agreed with the statement, whilst similar views were expressed by another $16(12.4 \%)$ participants, who agreed strongly. Only 18 (14\%) participants disagreed. These results suggest that the existing public sector SCM strategy has been successful in promoting responsiveness to end-customer needs. It is also evident as per Figure 3 that SCM has resulted in conformity with relevant laws, and in enhancing accountability. In all, 112 $(86.8 \%)$ respondents believed that SCM has led to accountability, whilst 110 (85.3\%) supported the statement that SCM resulted in policy conformity. Only a minority $(n=4 ; 3.1 \%)$ of participants were not in support of the statement, whilst $13(10.1 \%)$ were uncertain. Again, only six $(4.7 \%)$ participants disagreed with the statement that the introduction of SCM had enhanced conformity with the law, whilst $13(10.1 \%)$ were unsure. Therefore, it is concluded that the latter has rectified some of the shortcomings of previous purchasing models, namely, lack of accountability and nonadherence to the legal framework, which amounted to regulatory flaws (Ambe \& Badenhorst-Weiss 2012:242-243; De Lange 2011; Stemele 2009:68). Surprisingly, these findings 
contradict recent claims made by AGSA that, amongst others, there is poor administration, poor financial management, financial mismanagement and a lack of conformity to laws. Similarly, the findings of Migiro and Ambe (2008:236) and Tshamaano (2012:48-51), who claim that there is still nonadherence to law and a lack of accountability in this new procurement model, are rejected. It can therefore be concluded that SCM in public sector organisations has achieved one of its goals: elevation of principles of good governance.

According to Figure 4, it was found that 45 (34.9\%) participants were uncertain whether the role-players possess sufficient knowledge to carry out their tasks. This revelation pointed to the question of whether or not proper practices were in place if it was not known whether stakeholders possess required knowledge, whilst 41 (31.8\%) participants believed that they had insufficient knowledge. On the other hand, 43 (33.3\%) participants were confident (agreed and strongly agreed) that the role-players had sufficient knowledge. It is assumed that the limited knowledge that they had achieved was purely by 'default' because of the reasonable amount of time that the majority of them $(n=81$; $61.9 \%$ ) had spent at their positions. Figure 4 indicates that only $19(14.7 \%)$ participants stated that the SCM role-players were adequately trained. This finding calls for a specific training recommendation using approved metrics as a measurement tool to ascertain the adequacy of training. The same view was expressed by five (3.9\%) of the participants, who strongly agreed with the statement. However, slightly more than half of the participants $(n=65 ; 50.4 \%)$ disagreed that sufficient training was provided. This view was supported by $16(12.4 \%)$ participants, who strongly disagreed that they had received adequate training. This finding is a worrying factor, because according to Nkwanyana (2017:9), it is through training that the skills and competencies of employees could be promoted. Moreover, transforming the attitudes and behaviours of employees increases their capacity to work towards the realisation of organisational goals (Obi-Anike \& Ekwe 2014:68). It is clear that the studied departments do not embrace the principles of resource-based theory, which suggests that the abilities of the human resources should be enhanced in the interest of achieving SCA. Figure 4 again shows that only $37(28.7 \%)$ participants agreed with the

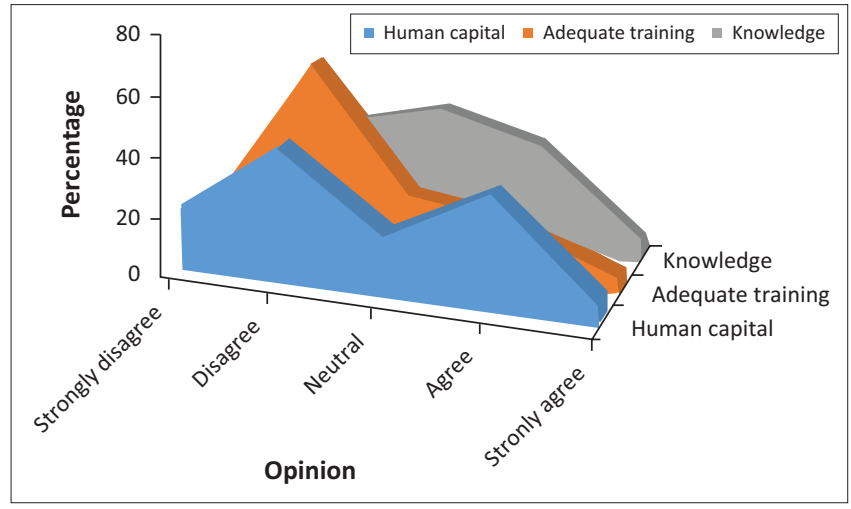

FIGURE 4: Human resource capability. statement that there was adequate human capital. Only seven (5.4\%) strongly agreed, 21 (16.3\%) strongly disagreed, whilst almost half $(n=44 ; 34.1 \%)$ disagreed with the statement. These findings are in line with the findings of Fourie and Poggenpoel (2016:6), suggesting that there is a capacity deficiency in public sector. This manpower deficiency, according to Husby (2007:53), is a constraint, which according to Ainapur et al. (2012:99) hinders the attainment of organisational goals. The major concern, however, is not the limited human resources. It is whether or not the organisation is aware of this constraint or limitation. If so, it is necessary to ask whether they have effective measures in place to maximise their capacity through interventions such as subordination, increasing aptitude and continuous system improvement. Again, these findings suggest a weakness in the SCD of this sector. It appears that the resources of an organisation are not positioned well enough to attain the desired output over time, as suggested by Melnyk et al. (2014:1889). According to these authors, strategic decisions should be taken during SCD to align its resources and processes in such a way that the desired output level can be attained over time.

\section{Discussion}

It has been found that the SCM system is characterised by a high level of accountability, conformity to relevant laws, transparency, responsiveness and participation. A high score in the above-mentioned characters, ranging from 112 $(86.8 \%)$ to $92(71.3 \%)$, was attained by the participants. Most of the participants $(n=112 ; 86.8 \%)$ felt that the introduction of SCM had led to accountability. Conformance to laws was ranked the second highest score, at 110 (85.3\%), whilst transparency received the third highest score at 109 (84.5\%). Again, 92 (71.3\%) participants felt that the introduction of SCM had led to stakeholder participation in decision-making that affected them. Overall, it was noted that SCM is in line with the basic requirements of good governance. It could therefore be concluded that it has achieved one of its goals, which is promotion of the principles of good governance. On the other hand, there are worrying indicators of the future collapse of the system. Although National Treasury Regulations 16A4 and 16A5 prescribe the establishment of a separate SCM unit and training of SCM officials thereof, it is worrying that findings suggest that to date not much effort has been devoted to aligning support structures for the attainment of SCM's strategic goal. This is evidenced by $65(50.4 \%)$ participants reacting negatively to the issues of availability of human capital. Just less than half $(n=37 ; 28.7 \%)$ of the participants supported this statement. Again, not much care has been taken to build capacity through training. In all, 81 (62.8\%) participants rejected the statement that role-players were being trained adequately. The same was reported in 2008, 2012, 2014 and again in 2016, where the majority of officials lacked skills in SCM, thus resulting in non-compliance with laws (Dlova \& Nzewu 2014:5; Migiro \& Ambe 2008:230; Poggenpoel 2016:6; Tshamaano 2012:46). In this study, the majority of the participants $(n=45 ; 34.9 \%$ and $n=41 ; 31.8 \%)$ 
were either unsure of or disagreed with the statement of availability of sufficient knowledge with respect to SCM. This finding poses questions regarding the capability or competency of human resources, and whether or not the public sector organisations are likely to sustain attainment of SCM goals. Again, a report of this nature was found in 2008, where administrative staffs were reported as incompetent in carrying out their own functions (Migiro \& Ambe 2008:230). Investment in competence could assist this sector to enhance its SCM performance (Kumar \& Nambirajan 2013:86). The current study employed a questionnaire survey to source data. That being said, the positive outcome in relation to good governance whilst a support structure is not in place thus becomes questionable. Rather, it is not expected that the system would achieve one of its primary goals of good governance when the competence of SCM practitioners is in limbo. Although the use of a questionnaire is advantageous because of its convenience, fastness and cost-saving, in this study the absence of researchers during question-answer session is noted as a weakness, because the researchers could not pose further questions and/or clarify contradictory answers. However, this risk could be curtailed by piloting the questions with a small number of participants. Again, the use of closed-ended questions and the absence of detailed introductory statements before each question were noted as deficiencies. This led to the possibility of each question being interpreted differently by different respondents, thus causing a lack of common base. As such, it weakened the foundation of sound conclusions. In addition, email receipt of some responses could have led to participants being biased in their responses, and not revealing the true sense of the matter under study.

\section{Direction for future research}

The primary findings of this study portray reasonable improvement in conformance to the elements of good governance as opposed to their investments in human capital. However, the secondary findings of the study that reflected disturbances in this system are not underestimated. As such, an intense investigation is recommended to look into this matter and at the standard operating procedure (SOP) versus the capability of support structures, such as the total number of human resources, their skills and knowledge, and the effect of continuous training on performance. It is recommended that the use of interviews or observatory research should be adopted as a methodology of study to gain an in-depth knowledge of the root causes of reported irregularities and deficiencies mayhem.

\section{Conclusion}

The study aimed to assess the status of SCM in relation to issues of good governance and human resource capability to achieve efficiency and effectiveness of this model to determine what could be the underlying factors that have given rise to the reported irregularities and deficiencies. The study adds to other existing scientific evidence by examining the effect of
SCM in public establishments. Through this study, SCM knowhow is advanced, to be utilised through management in various organisations. The study found contradictory outcomes regarding the current public knowledge of SCM turmoil. The study findings reflect that the SCM system reasonably operates within the requirements of good governance because there is enhanced accountability, conformity to relevant laws, transparency, responsiveness and customer participation. Thus, the elevation of principles of good governance has been achieved. However, there are worrying factors of human resource deficiency, insufficient knowledge regarding the processes employed within SCM, and lack of adequate training of SCM practitioners. Notwithstanding, it is concluded that although the introduction of SCM has resulted in an identifiable improvement in the procurement processes of public sector organisations, much is still required from authorities in this sector in terms of aligning and capacitating their human capital so as to take advantage of SCM for enhanced service delivery now and in the future.

\section{Acknowledgements}

The authors acknowledge the support and guidance provided by B. Nkwanyana, a University of KwaZulu-Natal PhD candidate, who since the start of the research project has been the support system and mentor. The authors also acknowledge Dr S. Chetty of University of South Africa who provided technical support and shed light on the do's and don'ts of this research project.

\section{Competing interests}

The authors have declared that no competing interests exist.

\section{Authors' contributions}

N.S.N. was the main researcher in this article, whilst A.T.A. was the advisor. A.T.A. contributed to this article by providing required necessary support and direction.

\section{Ethical consideration}

A level two ethical clearance was obtained from DUT to conduct this research (reference number FREC 231/216FREC).

\section{Funding information}

N.S.N. received a postgraduate support grant from the Durban University of Technology (DUT) where he was a student.

\section{Data availability statement}

Data sharing was not applicable to this article as no new data were created or analysed in this study.

\section{Disclaimer}

The views and opinions expressed in this article are those of the authors and do not necessarily reflect the official policy or position of any affiliated agency of the authors. 


\section{References}

Ainapur, B., Singh, R.K. \& Vittar, P., 2012, 'Strategic study on enhancement of supply chain performance', International Journal of Business Insights and Transformation 5(1), 98-106.

Ambe, I., 2009, 'An exploration of supply chains management practices in the central district municipality', Educational Search and Review 4(9), 427-435.

Ambe, I.M. \& Badenhorst-Weiss, J.A., 2012, 'Procurement challenges in South African public sector', Journal of Transport and Supply Chain Management 6(1), 242-261. https://doi.org/10.4102/jtscm.v6i1.63

Auditor-General of South Africa, 2018/2019, Enhanced mandate for enhanced accountability, viewed 29 November 2019, from https://pmg.org.za/committeemeeting/29037.

Baum, J., 2010, Supply chain futures: The master of complexity, MHD Supply Chain Solutions 40(1), 20-21.

Bester, A., 2007, 'Efficiency in the public sector: An analysis of performance measurements employed by Western Cape provincial treasury', Master's dissertation, University of Stellenbosch, Stellenbosch.

Bless, C., Higson-Smith, C. \& Sithole, S.L., 2013, Fundamentals of social research methods: An African perspective, 5th edn., Juta, Cape Town.

Chopra, S. \& Meindl, P., 2010, Supply chain management: Strategy, planning and operation, 4th edn., Pearson Education, Hudson, New York.

Chou, Y.C., Lu, C.H. \& Tang, Y.Y., 2012, 'Identifying inventory problems in the aerospace industry using the theory of constraints', International Journal of Production Research 50(16), 4686-4698.

Christopher, M., 2005, Logistics and supply chain management: Creating value-adding networks, Prentice Hall, Harlow.

Colbert, B., 2004, 'The complex resource based view: Implications for theory and practice in strategic human resource management', Academy of Management Review 29(3), 341-358

Crowe, S., Creswell, K., Robertson, A., Husby, G., Avery, A. \& Sheikh, A., 2011, 'The case study approach', BMC Medical Research Methodology 11(1), 100. https:// doi.org/10.1186/1471-2288-11-100

De Lange, S., 2011, 'Irregular state expenditure jumps 62\%', Business Day, viewed 11 July 2016, from http://www.smartprocurement.co.za/irregular_state_ expenditure_jumps_62.php\#sthash.Ja5iM9Oa.dpbs.

Department of National Treasury, 2004, Supply chain management: A guide for accounting officer/authorities, Department of National Treasury, Pretoria.

Department of National Treasury, 2005, National treasury regulations, Department of National Treasury, Pretoria.

Dlova, V. \& Nzewu, O., 2014, 'Developing and institutionalizing supply chain management procedures: A case study of the Eastern Cape Dept of Roads and Public Works', Africa's Public Service Delivery and Performance Review 2(1) 3-160. https://doi.org/10.4102/apsdpr.v2i1.40

Fawcett, S.E., Ellram, L.L. \& Ogden, J.A., 2007, Supply chain management: From vision to implementation, Prentice Hall, Upper Saddle River, NJ.

Fourie, D. \& Poggenpoel, W., 2016, 'Public sector inefficiencies: Are we addressing the root causes?', South African Journal of Accounting Research 31(3), 169-180. https://doi.org/10.1080/10291954.2016.1160197

Handfield, R.B., Monczka, R.M., Giunipero, L.C. \& Patterson, J.L., 2011, Sourcing and supply chain management, 5th edn., South-Western Cengage Learning, Boston, MA.

Hearnshaw, E.J.S. \& Wilson, M.J.S., 2013, 'A complex network approach to supply chain network theory', International Journal of Operations and Production Management 33(4), 442-469. https://doi.org/10.1108/01443571311307343

Hugos, M., 2011, Essentials of supply chain management, 3rd edn., Wiley, Hoboken, MJ. https://doi.org/10.1002/9781118386408

Husby, P., 2007, 'Competition or complement: Six Sigma and TOC', Material Handling Management 62(10), 51-55.

Institute of Local Government Management of South Africa, 2010, Submission to the parliamentary public hearings on coordinated service delivery, ILGM, Sandton.

Isoraite, M., 2005, 'Evaluating efficiency and effectiveness in transport organizations', Transport Journal 20(6), 240-247. https://doi.org/10.3846/16484142.2005.9638027

Kumar, R., 2011, Research methodology: A step-by-step guide for beginners, 3rd edn., Sage, London.

Kumar, C.G. \& Nambirajan, T., 2013, 'Supply chain management components, supply chain performance and organizational performance: A critical review and development of conceptual model', International Journal on Global Business Management and Research 2(1), 86-96.

Lee, C.W., Kwon, I.G. \& Severance, D., 2007, 'Relationship between supply chain performance and degree of linkage among supplier, internal integration and customer', Supply Chain Management: An International Journal 12(6), 444-452. https://doi.org/10.1108/13598540710826371

Li, S., Nathan, B.R., Nathan, T.S.R. \& Rao, S.S., 2006, 'The impact of supply chain management practices on competitive advantage and organizational performance', An International Journal of Management Science 34(2), 107-204. https://doi.org/10.1016/j.omega.2004.08.002
Lichocik, G. \& Sadowski, A., 2013, 'Efficiency of supply chain management: Strategies and operational approach', Scientific Journal of Logistics 9(2), 119-125.

Lockett, A., Thompson, S. \& Morgenstern, U., 2009, 'The development of the resourcebased view of the firm: A critical appraisal', International Journal of Management Reviews 11(1), 1468-2370.

Marshall, R.E., Gooley, T.B., Wayne, M., Frazelle, E., Hammer, M.M. \& Finley, J., n.d. 'Supply chain management: Analyzing industry and air force metrics global logistics support - The GLSC: Operational supply chain management', Air Force Journal of Logistics xxxi(3), 1-16.

Mbanje, S. \& Lunga, J., 2015, Fundamental principles of supply chain management, Van Schaik, Pretoria.

McCarthy, N., 2006, Report of the Auditor-General. Free State, Bloemfontein.

Mele, C., Pels, J. \& Polese, F., 2010, 'A brief review of systems theories and their managerial applications', Service Science 2(1-2), 126-135. https://doi.org/ 10.1287/serv.2.1_2.126

Melnyk, S.A., Narasimhan, R. \& DeCampos, H.A., 2014, 'Supply chain design: Issues, challenges, frameworks and solutions', International Journal of Production and Research 52(7), 1887-1896. https://doi.org/10.1080/00207543. 2013.787175

Mentzer, J.T., DeWitt, W., Keebler, J.S., Min, S., Nix, N.W., Smith, C.D. et al., 2001, 'Defining supply chain management', Journal of Business Logistics 2(22), 1-25. https://doi.org/10.1002/j.2158-1592.2001.tb00001.x

Migiro, S.O. \& Ambe, I.M., 2008, 'Evaluation of the implementation of public sector supply chain management and challenges: A case study of central district municipality, North West province, South Africa', African Journal of Business Management 2(12), 230-242.

Moon, S., 2004, 'The relationships among manufacturer product strategy, supply chain structure and supply chain inventory', Asia Pacific Journal of Marketing and Logistics 16(2), 20-45. https://doi.org/10.1108/13555850410765168

Nagy, J., 2010, 'Types of supply chains and tools for management: Empirical study', Doctorate dissertation, Corvinus University of Budapest, Budapest.

Nel, J., 2010, 'Developing a conceptual framework to analyze supply chain design practices', PhD thesis, University of South Africa, Pretoria.

Nkwanyana, B., 2016, 'An analysis of training and development in the public sector: A case study of government communication and information system in the KwaZuluNatal province', Master's dissertation, University of KwaZulu-Natal, Durban.

Nyaga, J., 2015, 'Non-financial reward and employee retention in private primary schools in Kenya (Kiambu county)', International Journal of Management and Commerce Innovations 3(1), 240-254.

Obi-Anike, H. \& Ekwe, M., 2014, 'Impact of training and development on organizational effectiveness. Evidence from selected public sector organizations in Nigeria', European Journal of Business and Management 6(29), 66-75.

Parliament of the Republic of South Africa, 2019, Joint SCOPA and standing committee on appropriations concerned about 2018/2019 audit outcomes, viewed 29 November 2019, from https://www.parliament.gov.za/press-releases/jointscopa-and-standing-committee-appropriations-concerned-about-201819-auditoutcomes.

Pathak, S.D., Day, J.M., Nair, A., Sawaya, W.J. \& Cristal, M.M., 2007, 'Complexity and adaptivity in supply networks: Building supply network theory using a complex adaptive systems perspective', Decision Sciences Institute 38(4), 547-580. https:// doi.org/10.1111/j.1540-5915.2007.00170.x

Sarkis, J., Zhu, Q. \& Lai, K., 2011, 'An organizational theoretic review of green supply chain management literature', International Journal of Production Economics 130(1), 1-15. https://doi.org/10.1016/j.ijpe.2010.11.010

Sekaran, U., 2006, Research methods for business: A skill building approach, Joh Wiley and Sons, New Delhi.

Shaffer, K.J. \& Dalton, P.M., 2012, 'Can adopting supply chain management practices improve supply chain efficiency?', International Journal of Business, Marketing and Decision Sciences 2 (2 Fall), 99-120.

Smart Procurement, 2011, SA public procurement: Poor value for money, viewed 03 March 2016, from https://www.smartprocurementworld.com.

Stemele, B.M., 2009, 'Assessing good governance in procurement at Lejweleputswa District Municipality', Master's dissertation, University of Stellenbosch, Stellenbosch

Stock, J.R. \& Boyer, S.L., 2009, 'Developing a consensus definition of supply chain management: A qualitative study', International Journal of Physical Distribution \& LogisticsManagement39(8),690-711.https://doi.org/10.1108/09600030910996323

Tshamaano, V., 2012, 'Impact of supply chain management on service delivery: The case of provincial department of economic, development, environment and tourism in the Limpopo province', Master's dissertation, University of Limpopo, Polokwane, pp. 1-81.

Wisner, J.D., Tan, K.C. \& Leong, G.K., 2012, Principles of supply chain management: A balanced approach, Cengage Learning, Las Vegas, NV.

Yang, Y., 2009, 'An investigation of group interaction functioning stimulated by transformational leadership on employee intrinsic and extrinsic job satisfaction: An extension of resource based theory perspective', Social Behaviour and Personality. An International Journal 37(9), 1259-1278. https://doi.org/10.2224/ sbp.2009.37.9.1259 